\title{
Outro lapso de tempo: as novas Histórias da Literatura
}

Ana Cláudia Munari Domingos ${ }^{a}$

\section{Resumo}

A partir das proposições de novas histórias da literatura, plurais, periféricas, revisitadas, que historiadores como Hugo Achugar, Nelson Vieira e Siegfried Schmidt trouxeram à tona no final da década de 90, este artigo faz uma pequena revisão das histórias da literatura brasileira publicadas naqueles anos e na década seguinte, comparando-as. Na mesma perspectiva, o texto ainda coloca em discussão as relações entre as áreas de história, teoria e crítica literária e apresenta as então recentes tentativas do exercício de micro-história no campo da literatura.

Palavras-chave: História da literatura brasileira, Micro-histórias, Crítica literária. 


\begin{abstract}
Estes textos não existem nas prateleiras das estantes: são processos de significação que só se materializam na prática da leitura. Para que a literatura aconteça, o leitor é tão vital quanto o autor.

Terry Eagleton.

As Histórias da Literatura têm sempre razão. Alás, elas têm sempre razão. Mas não completamente.

Robert Ponge ${ }^{1}$.
\end{abstract}

${ }^{1}$ Palestra: "As vanguardas II - Dadaísmo e Surrealismo", noSeminário Internacional $A$ aventura da modernidade. Em 28 de junho de 2008.
Depois do sermão de Jauss em sua aula inaugural na Universidade de Konstanz em 1967 - no qual ele formalizava pesadas críticas às formas tradicionais da História da Literatura -, teóricos e estudiosos da área assistiram a um autêntico exercício de alteridade da hermenêutica tradicional para enxergar o "outro" de sua própria existência: o leitor. O sopro de Jauss desejava recuperar a História da Literatura de sua existência miserável, garantindo-lhe vitalidade a partir da dependência de seu próprio objeto de estudo - a Literatura - a um organismo vivo: a leitura.

Se outros estudiosos já vinham sinalizando para a inclusão do leitor como instância de sentido no processo hermenêutico - como Umberto Eco, em 1962, em Obra aberta -, apontando o caráter comunicacional do texto literário, Jauss foi o primeiro a provocar uma repercussão nas construções da História da Literatura. À medida que se renunciava ao sentido fixo da obra - na perspectiva da compreensão imanente do texto literário - em vista do entendimento de que o objeto estético só existe na confluência entre texto e leitor, Jauss supunha o objeto da História da Literatura justamente nessa intersecção fluida, que depende de um conjunto de relações entre o receptor e seu entorno, em uma perspectiva espaço-temporal - em uma dinâmica entre presente e passado. Jauss incitava então à visão pragmática do texto pela História da Literatura.

Grande parte desses teóricos da História da Literatura respondeu à provocação de Jauss reafirmando sua posição, mesmo quando eles supõem certa desconstrução de seu pensamento. Assim, Siegfried Schmidt, Claus-Michel Ort, Gebhard Rusch, Friederike Meyer, Niklas Luhmann, Hans Ulrich Gumbrecht e outros historiadores alemães da Literatura terminaram por também se opor à exigência caduca da diacronia 
linear - cega para o mundo tridimensional - aceitando a perspectiva da recepção e seus entornos. A partir da inclusão de ideias como as de simultaneidade, sistemas, construtividade, moldura, de mentalidade, enfim, tornou-se visível uma nova preocupação entre esses estudiosos: o limite do discurso historiográfico. Entremeando as alocuções dessas teorias há um pensamento que aponta para a consciência da arbitrariedade, e, assim, a busca consequente por teorias e diretrizes que limitem e legitimem o fazer histórico da Literatura acaba por transformar-se em mote desses estudiosos.

Enquanto, de um lado, teóricos como Heidrun Krieger Olinto (1996) apontam para um revigoramento dos estudos teóricos sobre a História da Literatura a partir da provocação de Jauss, de outro, essa mudança de paradigma que desemboca em novas teorias age sobre o exercício da disciplina, refreando a construção de novas Histórias da Literatura. Essa contradição pode ser imaginada na hipótese de um alargamento de horizontes versus o estreitamento do alcance: se antes a mancha plana do texto era o único ponto de visão dos estudiosos da Literatura, a inclusão da perspectiva do leitor amplia literalmente o campo e enodoa os limites da interpretação. A História da Literatura encontra, nesse momento, um objeto alargado tridimensionalmente - a Literatura e sua interpretação simultânea, porque diacrônica e sincrônica - e acaba por perder a capacidade de abarcar o todo dessa visão.

Essa diluição da totalidade ${ }^{2}$, substituída pelas ideias de imaginário, de moldura, de sistemas, de mentalidade, de contingência, é que transforma o exercício do historiador da Literatura em melindre: ora, na impossibilidade de abarcar um todo, o discurso histórico pressupõe, então, uma seleção; e escolhas, por seu turno, implicam em desconsiderações, lacunas, parcialidades, montagens. Por outro lado, ao historiador, também um leitor da literatura e do mundo, abrem-se novas possibilidades de configuração, que incluem perspectivas, senão pessoais, pelo menos particulares ou individuais - para não dizer subjetivas.

${ }^{2}$ Aqui não se discute a existência de uma totalidade discursiva em qualquer ponto da História, mas a intuição e a intenção de que ela possa ser exercida através do discurso histórico.

É por essa arbitrariedade do objeto e sua interpretação, aliada ao foro renovado do historiador também como um leitor, que estudiosos como Schmidt (1996) incluem a questão da legitimação. Se a perspectiva muda do factual para o sujeito - que elege, recorta, organiza, estrutura - a legitimação 
torna-se um princípio de regulação do exercício histórico. Para Schmidt, quatro princípios devem nortear a escrita de histórias da literatura: (a) toda construção histórica deve ser legitimada, (b) orientada na perspectiva de inter-relação entre agente-texto-contexto e na relação entre esses e seus respectivos sistemas e o sistema literário, e, (c) na análise do sistema literário que objetiva compor essa história, toda a série de meios de comunicação daquela sociedade deve ser levada em conta, (d) chegando a um objeto que deve ser aplicável além de seu próprio contexto.

Schmidt serve como exemplo da união entre essa nova perspectiva pragmática da História da Literatura e a preocupação com os limites desse exercício. Nessa esteira, algumas novas teorias surgidas posteriormente buscam formas de recuperar a prática do historiador da literatura, resolvendo a questão da seleção e de sua legitimação. Na medida em que tanto reformular como recontar a História da Literatura pressupunham encontrar o que havia sido perdido pela perspectiva imanente, e que tal seleção deveria funcionar sobre a contingência, parcialmente narrada, Hugo Achugar e Nelson Vieira trabalham com a perspectiva de inclusão, como estratégia para a escrita de novas histórias. Para ambos, o foco deveria recair sobre os excluídos do discurso histórico tradicional.

Achugar (2003) volta seu olhar para todo um imaginário coletivo que ele julga ter sido abafado pelo discurso histórico tradicional e que precisa ser realocado; é no discurso desses excluídos que está a verdadeira identidade cultural das nações latino-americanas: na voz do índio, do negro, da mulher, do analfabeto. Se a produção da Arte, como prega Achugar, faz parte do processo de construção de uma nação, a palavrachave aqui é imaginário: ele não apenas formalizou a Arte, mas interpretou-a e constituiu o discurso histórico sobre ela. Novas histórias da literatura, pois, requerem a reconstrução do imaginário ignorado.

Nelson Vieira (2003) apresenta propósito similar ao de Achugar - a inclusão de novas histórias da literatura -, mas por outra via: a do hibridismo. O híbrido, aqui, também seria uma contraposição ao discurso autoritário, porque entra em choque com o homogêneo - princípio de unicidade da força que instituiu as identidades nacionais. As divisões sociais, as diferenças culturais, desaparecem no procedimento 
historiográfico quando, no processo de hierarquização desses valores, a expressão mais valorizada é a tradicional, que pertence ao grupo dominante. A cultura, diferente e plural, é homogeneizada pelo discurso. O híbrido não é a mistura dessas forças, mas a colisão entre elas, o terceiro elemento. A escrita de novas histórias da literatura, dessa forma, precisa invocar essas vozes não canonizadas, com o intuito de provocar a diferença que se opõe à desigualdade, à hierarquização, ao jugo.

A resposta à provocação de Jauss toma uma forma possível, quase quarenta anos depois (embora talvez se tenha superado seu horizonte de expectativas): as novas Histórias da Literatura, então, metodologicamente, deveriam abarcar uma seleção legitimada do amplo sistema literário, que por sua vez está inter-relacionado a vários outros sistemas de forma tridimensional (ou em rede), em uma perspectiva temporal também tridimensional - diacrônica, sincrônica e simultânea. Tematicamente, haveria a sugestão de abarcar os textos excluídos do discurso histórico tradicional, posicionando o imaginário perdido e o híbrido cultural.

Enquanto os teóricos da História da Literatura entrelaçam suas conclusões, os historiadores arqueiam os ombros com o peso da tarefa, calculam o passo no terreno instável, buscando o equilíbrio perdido no contrapeso e na desacomodação. Frente ao quadro de portas que se abrem e setas que apontam os caminhos múltiplos da escrita de histórias da Literatura, agora no plural, a provocação que então se coloca é a ousadia da pena - uma pena que tanto é instrumento quanto é castigo - e que levou Schmidt (1996, p. 101) a questionar no título de um de seus artigos: "Escrever histórias da literatura: um projeto necessário e impossível?".

Dando um rápido olhar ao universo das Histórias da Literatura Brasileira publicadas nos limiares do século XXI, e que, portanto, respondem (ou não) àquilo que é proposto a partir das novas teorias, podemos evocar, de forma simplista, duas correntes diversas. De um lado, uma escrita que ainda segue o mesmo propósito, já criticado por Jauss em 1967, de aglomerado enciclopédico de informações, e que talvez reúna os dois tipos mencionados por Jauss naquela conferência em Konstanz - que ou organizam por tendência, gêneros, escolas e tratam os autores e obras cronologicamente dentro desses esquemas, ou ordenam todos os dados de forma linear. 
Esses seriam os volumosos livros de História da Literatura Brasileira que perseguem o ideal totalizante de Sílvio Romero, José Veríssimo, Afrânio Coutinho, Antônio Cândido, Alfredo Bosi, para citar os mais representativos, e que talvez poderiam terminar em José Aderaldo Castello, em 1999, quando há muito já se pensava que o modelo estava gasto. No outro lado, estão as obras que buscam todos parciais, em uma tendência provavelmente inaugurada pelo movimento modernista, de repensar a Literatura e que, lá, funcionava em uma perspectiva de rever sua formação, e que, mais recentemente apenas mantém a prática de eleger como objeto um gênero, uma escola ou um período - como tendência ou como lapso de tempo -, um autor, até mesmo a história de uma única obra.

Assim, podemos elencar, no quesito volumoso e totalizante, as obras de Luiz Roncari e Carlos Nejar. A de Roncari, de 2002, Literatura Brasileira: dos primeiros cronistas aos últimos românticos, é a segunda edição, revista e ampliada daquela de 1995; a de Nejar, História da Literatura Brasileira, é de 2007, e também traz um subtítulo cujo horizonte perfaz uma linha ainda mais extensa que a de Roncari: "Da carta de Pero Vaz de Caminha à contemporaneidade". Como tamanho não é documento - e ironicamente se pode dizer que literalmente não é -, o volume de Roncari é apesar disso bem maior do que o de Nejar. Ainda dentro desse mesmo contexto de abarcar uma História da Literatura desde o momento em que ela recebe a alcunha até o ponto em que o distanciamento crítico, ou a esfera da legitimidade, ou a cadeira ainda ocupada por um provável objeto de estudo, permita, pode-se citar algumas obras mais modestas no quesito tamanho, como a de Luciana Stegagno-Picchio, em edição revisada de 1997, História da Literatura Brasileira, cuja primeira edição data de 1972, e que é apenas aparentemente pequena - sua letra miúda em corpo 9,5/10,5 e as páginas em papel valobible francês $40 \mathrm{~g}$ permitemna alcançar 743 páginas em capa dura -; e talvez ainda se possa citar nessa categoria mais verdadeiramente o livro de 89 páginas de Luís Augusto Fischer, Literatura Brasileira, de 2003.

Pensando esses quatro volumes, podemos reorganizá-los sob outro critério: o propósito. Assim, as obras de Roncari e Fischer se aproximam, de um lado, e a de Nejar e StegagnoPicchio, de outro. As primeiras agregam-se pela perspectiva do propósito didático, embora cada um se dirija declaradamente a 
públicos diferentes. Roncari obedece à tendência da instituição em que está inserido, a USP, de oferecer aos professores material de ensino; destina-se, portanto, às escolas de Ensino Médio, seus professores e acadêmicos dos cursos de Graduação. Fischer, por sua vez, oferece seu livro àqueles que sabem que ler literatura é importante, leigos, desesperados de última hora às portas do vestibular, indivíduos preocupados em estabelecer uma conversa razoável quando o tema é Literatura.

Stegagno-Picchio e Nejar, por outro lado, aproximamse na tradição reverenciada desde os primeiros cronistas das Letras Brasileiras, representada na necessidade que os literatos e eruditos apresentavam de legitimarem suas próprias versões da História da Literatura. Stegagno-Picchio, como autoridade estrangeira sobre o assunto, não poderia de outra forma referendar seus estudos acerca da Literatura Brasileira que não oferecer um panorama histórico, capaz por si só de revisitar tendências, temas, autores e obras. Já Nejar tomou o mote a partir de um ponto de vista intrassistema, porque escritor, e também como um voraz leitor de Literatura. Ainda sob outro critério, é possível retirar desse agrupamento a obra de Fischer, já que de maneira alguma pode ser comparada aos outros três na perspectiva do alcance a que se propõe em sua resumidíssima composição.

Estruturalmente, as outras três obras são extremamente similares: dividem-se em capítulos conforme as Escolas, mesmo que sob títulos um tanto particulares - caso de $A$ praça e o púlpito, de Roncari, ou Bahia, ilha da maré, de Nejar, ambos falando sobre a Literatura Colonial. Todos têm como ponto de partida a carta de Caminha, mas diferentes pontos de chegada. No caso de Roncari, que oferece um livro de iniciação ao estudo da literatura brasileira, assim se justifica o corte em José de Alencar, o último romântico, e Martins Pena, já que ele reúne no último capítulo o romance e o teatro do período. De resto, o interessado deve buscar à parte, se deseja ultrapassar a fase de iniciação. Luciana finda sua trajetória onde era possível: no ano de 1996, apenas um antes da data de publicação. Talvez a distância física - ela residia na Itália - permitiu-lhe desobrigarse do distanciamento temporal, o que não é o caso de Nejar. Sua justificativa para parar em 1960 é a falta de imparcialidade no exame de um oceano em que ele ainda é navegante, o que leva àquela questão de uma cadeira ainda ocupada. 
A proposta das três obras não é diferente: abarcar o conjunto da Literatura Brasileira em um movimento diacrônico, a partir dos períodos literários, e sincrônico, quando se detém em cada autor - vida, obra, comentários críticos. A diferença a que se propõe Roncari é de mudar o paradigma do livro didático, com ganhos de profundidade e análise; a singularidade da obra de Stegagno-Picchio é ser escrita por uma estrangeira com uma visão de conjunto da nossa cultura literária raramente encontrada entre nós; e a distinção de Nejar é preencher as lacunas sobre o pouco que se sabe da Literatura Brasileira, sem o ranço acadêmico. A peculiaridade de Nejar, por tal, é a linguagem poética, os títulos rebuscados e a profusão nada acadêmica de citações as mais variadas.

Além disso, o poeta trabalha em uma evidente perspectiva de inclusão. No entanto, seus critérios para incluir os injustiçados pela crítica, como Coelho Neto, ou os difíceis de serem rotulados, como Sosígenes Costa, constroem-se em uma perspectiva de abarcar o maior número possível de autores, alcançando o objetivo de preencher lacunas. Fosse por desfazer equívocos críticos, não incluiria, por exemplo, o poeta Tyrteu Rocha, cujo traço exótico e curioso foi esquecido pelo tempo que delineia. Mas, se inova pela profusão de desconhecidos, salvos do esquecimento pela memória caridosa do poeta-leitor, a obra retrocede metodologicamente quando os capta de forma isolada e estanque, sem qualquer perspectiva de relação entre o sincrônico e o diacrônico.

Vozes acadêmicas relativamente uníssonas e equivalentes, nenhuma das três obras é capaz de responder aos anseios das novas teorias da História da Literatura, porque atendem à demanda da totalidade, do pendor enciclopédico, da linearidade, da visão plana que não faz correspondência entre os sistemas literário e social, mas apenas contextualiza, cita e julga, ainda na mesma perspectiva de estilo, época, tema, representação.

No outro grupo, em que se localizam as obras que não atendem à demanda da totalidade, raras obras se anunciam que possam enquadrar-se na disciplina História. Aliás, atualmente, a confusão entre Teoria da Literatura, Crítica Literária, Estudos comparados e História da Literatura começa pela confusão dos departamentos de Pós-Graduação - como o da USP, de Teoria Literária e Literatura Comparada e suas cinco linhas de pesquisa, que incluem a Crítica e a História da Literatura - e 
termina pelas prateleiras das livrarias e pelas seções ou assuntos dos websites que vendem livros. Buscar um livro de História da Literatura no website da Livraria Cultura, por exemplo, significa selecionar o assunto "Literatura nacional", em seguida, "teoria e crítica literária". Lá encontramos o assombroso resultado de mais de 3 mil obras (em português), que mostra na primeira página o romance Vidas secas ao lado de História concisa da literatura brasileira, inclui Os 10 livros que abalaram meu mundo - em que jornalistas, escritores, livreiros, agentes literários, pesquisadores e editores escolhidos falam sobre as obras que marcaram suas vidas - e termina em $O$ cortiço, este ladeado por Literatura comparada: reflexões, de Eduardo Coutinho. Na mesma lista, está o criativo e sugestivo título Com quantos tolos se faz uma República?, de Maria Marta Araújo, que logo propõe uma questão: é História ou História da Literatura? De acordo com a sinopse, o livro é uma "abordagem da micro-história e constrói uma trajetória para a vida do intelectual e político padre José Joaquim Correia de Almeida (1820-1905)", e completa: “a obra pode ser lida como uma espécie de história do pensamento político por via da literatura". A Literatura é aí objeto ou fonte de estudo? Se é fonte para a compreensão da vida do Padre Correia de Almeida, pertence à História, já que põe o Literário no campo do instrumento, retirando-o do foco principal, que é o campo social brasileiro.

As micro-histórias são talvez o único exercício da História da Literatura praticado atualmente no Brasil que corresponde às suas novas proposições, nesse caso, àquela que diz respeito a histórias literárias como partes legitimadas de um sistema de sistemas. São histórias de um gênero, como $O$ romance brasileiro, de Marisa Lajolo, de 2004 e História da poesia, de Alexei Bueno, de 2007, ou que tomam tópicos como objeto, como no caso de Literatura - História e Política, de Benjamin Abdala Júnior, também de 2007, que discute o engajamento dos escritores a partir da Modernidade, também a partir de um recorte temporal.

O caso da obra de Lajolo pode servir como referência para a ideia de que a inclusão da perspectiva do leitor - e todas as proposições que surgiram com os estudos da Estética da Recepção - abriu uma fenda nos rigorosos estudos da História da Literatura tradicional que permite uma nova configuração de seu exercício: as histórias de leitores ou de leitura. A história 
de Lajolo começa com a sua identificação como leitora, e é seu próprio percurso que ela segue, uma história de leitura. A literatura - os romances que ela leu - é o objeto de estudo, mostrado a partir de um ponto de origem - Inocência, de Taunay, que ela leu na adolescência - até A mulher que escreveu a Bíblia, de Moacyr Scliar, de 1999, o último livro que ela comenta. O percurso histórico não é o do romance brasileiro, portanto, mas uma trajetória particular de leitura do romance brasileiro. Por outro lado, se fica a dúvida sobre ser ou não uma História da Literatura, está aí inclusa a questão da simultaneidade, na própria perspectiva de ser uma história de leitura: o olhar do narrador parte de si mesmo, no momento da narração, para o objeto outro, a literatura, seu antes e seu então. E ainda desconstrói a perspectiva de linearidade, já que salta tanto de um momento literário a outro, representado por determinada obra, como de um ponto a outro da própria vida da narradora, conforme ela estabelece relações com as obras que leu.

Não haveria outra forma de Lajolo legitimar a seleção subjetiva que ela realiza do romance brasileiro senão pela abonação da leitura. Certamente que seus critérios evocam o cânone e a qualidade literária, e não poderia ser diferente em se tratando de uma estudiosa da literatura, de quem se espera rigor na escolha de obras. Mas, ao eleger seu cânone, Lajolo responde principalmente por sua curiosidade de leitora, que lhe permite citar Xangô de Baker Street, de Jô Soares, e Paulo Coelho, não referindo dele nenhuma obra específica, mas apenas esses best sellers contemporâneos que possibilitam ao leitor viajar por lugares distantes e exóticos. Ela também pode utilizar com parcimônia (porque é Marisa Lajolo) o critério do gosto, assumindo que gosta de Agatha Christie e Simenon, por exemplo. Nada de datas exatas, fontes fidedignas, referências rigorosas: quem manda é a memória do leitor.

Em uma época em que os teóricos, críticos e historiadores da literatura não são bacharéis literatos ou viajantes interessados, mas Doutores em Literatura, cuja tarefa de uma vida inteira tem por objeto o estudo das Letras, há muitas pessoas capazes de contradizer e jogar por terra qualquer anotação não comprovada e legitimada através de documentos e referências factuais. A facilidade de proceder a uma viagem de estudos não outorga a mais ninguém o status de intelectual, como aqueles que escreveram as primeiras Histórias da 
Literatura Brasileira; tampouco permite justificar pela distância espacial uma ausência ou ainda um equívoco por parte dos que têm por obrigação o levantamento criterioso de dados. E quando já se falou tudo de quase tudo, mas continua a se dizer que ainda falta muito para alcançar um todo que não existe, cada vez é mais difícil invocar uma nova relação com o passado - objeto da história - e ainda legitimá-la a gosto dos padrões atuais.

Por outro lado, o suporte da internet é acessível a grande parte da população, possibilitando a quem desejar a publicação de sua história, crítica, teoria ou ideia. Embora os espaços restritos da Academia (Universidades, agremiações literárias, revistas eletrônicas) são os mesmos virtualmente, cujos critérios de publicação permanecem os do livro, há muitos outros espaços disponíveis, e provavelmente mais acessados, para o pensamento subjetivo, opinativo e não legitimado de leigos e simpatizantes. Se a internet é o espaço do ilegítimo, a legitimidade do âmbito do livro mais se fortalece por contraposição.

Outra questão que se impõe é o alargamento do próprio objeto de estudo da História da Literatura. Se hoje esse exercício perdeu sua função de referendar uma nação, avultou-se seu papel de compor o próprio sistema que historiciza. À medida que elege um cânone, situa uma moldura, estabelece limites, a História da Literatura cria um objeto, cujos parâmetros dialogam com o sistema atual, que pode interferir na configuração do literário, desde o modo como se pensa o passado da Literatura até o que se espera dela e para onde ela vai. E pensar o que pode ser chamado de Literatura atualmente não é tarefa das mais simples.

O limite colocado por Jauss ainda em 1967, quando sugeriu a inclusão do leitor na perspectiva da História da Literatura, seria a experiência e o conhecimento prévio do leitor em relação ao texto no momento da leitura, e a forma como esse conhecimento, essas suposições, modificam-se a partir do texto, tanto para o leitor, quando ele se volta ao mundo novamente, quanto para o texto, que terá sua significação alterada por leituras sempre diferentes. A História da Literatura seria uma história dos horizontes de expectativas, em que não importaria a transformação da matéria factual, como na História tradicional, mas a mudança do próprio horizonte, as possibilidades de leitura, os comportamentos e as ideias antes e depois da leitura. 
Talvez seja possível adaptar o ideal de Jauss a uma prática factível atualmente. Tal narrativa buscaria os entornos do texto literário e em que medida eles afetaram e foram afetados pela existência - através da leitura - de determinada obra. Histórias como a das micro-histórias - que narram a partir de pontos de vista diferentes, mas não de forma episódica que permitem se enxergue a diferença e as relações entre os sistemas. Histórias que perguntem ao leitor contemporâneo sobre a correspondência entre a sua leitura e as possíveis leituras do passado - os significados que permanecem, os sentidos esgotados. Se o objeto estético pressupõe um leitor, as Histórias da Literatura deveriam ser histórias das experiências estéticas, e não de textos, meros artefatos estáticos nas estantes, como os pesados compêndios da História da Literatura tradicional. Esses ainda servem para as consultas, quando se esqueceu uma data, um nome, e certamente também para legitimar nossas referências. São memória, como os pendrives, são indicadores, como o Google, necessários nesses tempos de velocidade e voracidade. Mas não são livros de leitura, daqueles sobre os quais falava Jauss, capazes de modificar nossos horizontes de expectativa.

\section{REFERÊNCIAS}

ACHUGAR, Hugo. A escritura da História ou a propósito das fundações da nação. In: MOREIRA, Maria Eunice (Org.). Histórias da literatura: teorias, temas e autores. Porto Alegre: Mercado Aberto: 2003, p. 35-60.

ECO, Umberto. A obra aberta. [1962] São Paulo: Perspectiva, 2001. FISCHER, Luís Augusto. Literatura Brasileira. São Paulo: Abril, 2003.

GUMBRECHT, Hans Ulrich. Cual fénix de las cenizas o del canon clásico. In: SULLÁ, Enric. El canon literario. Madrid: Arco, 1998, p. 61-90.

História da Literatura: fragmentos de uma totalidade desaparecida? In: Histórias de literatura: as novas teorias alemãs. São Paulo: Ática, 1996, p. 224-239.

JAUSS, Hans Robert. História da Literatura como provocação à teoria literária. São Paulo: Ática, 1994. 
LAJOLO, Marisa. Como e por que ler o romance brasileiro. Rio de Janeiro: Objetiva, 2004.

LIVRARIA CULTURA. In: http://livrariacultura.com.br

NEJAR, Carlos. História da literatura brasileira. Porto Alegre: Copesul, 2007.

OLINTO, Heidrun Krieger. Interesses e paixões: histórias de literatura. In: Histórias de literatura: as novas teorias alemãs. São Paulo: Ática, 1996, p. 15-45.

. Voracidade e velocidade: historiografia literária sob o signo da contingência. In: MOREIRA, Maria Eunice (Org.). Histórias da literatura: teorias, temas e autores. Porto Alegre: Mercado Aberto: 2003, p. 23-34.

RONCARI, Luiz. Literatura Brasileira. [1995] São Paulo: EDUSP, 2002. SCHMIDT, Siegfried. Sobre a escrita de histórias da literatura. Observações de um ponto de vista construtivista. In: Histórias de literatura: as novas teorias alemãs. São Paulo: Ática, 1996, p. 101-131.

STEGAGNO-PICCHIO, Luciana. História da literatura brasileira. Rio de Janeiro: Nova Aguilar, 1997.

VIEIRA, Nelson. Hibridismo e alteridade: estratégias para repensar a história literária. In: MOREIRA, Maria Eunice (Org.). Histórias da literatura: teorias, temas e autores. Porto Alegre: Mercado Aberto: 2003, p. 95-114.

\section{Abstract}

Another lapse of time: the new Histories of Literature

This article is based on propositions of a new, plural, outlying, revisited history of literature, brought to light by historians such as Hugo Achugar, Nelson Vieira and Siegfried Schmidt in late 90's. It combines a short review and a comparative study of the history of Brazilian literature published in the 90's and 2000 decades. The article also discusses the connection that links literary criticism, theory and history, and presents recent attempts of micro-history practice in the field of literature at that time.

Keywords: History of Brazilian literature, Microhistories, Literature criticism 